\title{
Interpreting the concept of sedimentation in Husserl's Origin of Geometry
}

\author{
Johan Blomberg
}

\begin{abstract}
In the influential text Origin of Geometry, Edmund Husserl argues that even the invariant meaning found in theoretical disciplines like geometry has a historical becoming: through gradual abstraction and stabilization, ending in a completely rational discipline. This is a process which Husserl proposes is due to language and other symbolic systems. In the absence of a system allowing for stable communication of meaning, geometry or any other tradition would constantly have to begin anew. At the same time Husserl also sees the historical process of meaning stabilization in linguistic form as detrimental. It allows for a reception of an established meaning, which simultaneously entails the forgetfulness of the experiential basis and intuitive knowledge that made ideality possible in the first place. Husserl calls this Janus-faced dialectical process between discovery and forgetfulness sedimentation. This paper analyzes this concept in Origin of Geometry and places it in the context of Husserl's thought more generally. In contrast to Husserl's negative view of the effects that sedimentation has for an authentic meaning, I discuss four interpretations of sedimentation that provide more constructive perspectives on the concept. These interpretations also differ considerably from one another, a fact which speaks both to the richness and the tensions in Origin of Geometry.
\end{abstract}

Keywords: ideality, language, life world, meaning formation, phenomenology, sign systems, writing

\section{Introduction}

Origin of Geometry (Ursprung der Geometrie) is one of the last texts written by Edmund Husserl. Even though it remained incomplete at the time of his death in 1938, it was edited and published by Eugen Fink in the following year. ${ }^{1}$ In Origin of Geometry (Husserl, 1970b; henceforth "OG"), Husserl returns to the issue that sparked his philosophical career almost half a century earlier in Philosphie der Arithmetik: the possibility and status of ideal objects, like those found in geometry and mathematics. Such objects have the peculiar qualities of permanence and invariance: they are unaffected by empirical context and thereby always remain the same on every single use. Because of such features ideal entities have, ever since antiquity, been a major theme in philosophy, perhaps most famously expressed in Plato's distinction between the permanence of ideal forms and the transience of worldly entities. By addressing the topic of ideality, Husserl is thus not only returning to the starting point of his own thinking, but just as importantly to the origin of Western philosophy.

With Husserl's earlier works in mind, OG remains something of an outlier, possibly hinting at the initial steps on a new trajectory in his thinking (Lawlor, 2002a). This is mainly due to $\mathrm{OG}$ introducing features previously dismissed from phenomenological inquiry as crucially involved in the formation of ideal meaning. Among them are history, culture and language, all of which were regarded as empirically oriented matters, incapable of providing the absolute and incontestable validity, the elucidation of which is the fundamental goal for transcendental phenomenology (e.g. Husserl, 1983 [1913]). At the time of OG, however, Husserl's views on these matters are in, what might perhaps be best described as, a transitional

\footnotetext{
${ }^{1}$ Husserl's original manuscript dates from 1936 (Derrida, 1978 [1962]). Fink's version was published in Revue Internationale de Philosophie 1(2) with the title Die Frage nach dem Ursprung der Geomtrie als intentional-historisches Problem. A re-edited version of Origin of Geometry closer to the original manuscript is usually appended to the later editions of Husserl's monograph Crisis of the European Sciences and Transcendental Phenomenology (Husserl, 1970a).
} 
phase. This ambivalence is clearly shown in how he attempts to straddle the line between maintaining the integrity of ideal objects as truly ideal, but at the same time investigating how they take form and emerge in history. To this end, the concept of sedimentation is used to describe the gradual abstraction and stabilization of meaning in language (and in other symbolic systems like mathematical notation) that allows for ideality to be represented in a way that ensures that the same meaning is intended on every single use. While Husserl is adamant to emphasize the necessity of sedimentation for meaning to be stabilized and communicable across space and time, he also sees this as a process that entails a forgetfulness of the origin that made the sense in question possible in the first place.

By bringing matters of history and tradition into such a complex interplay with ideality, OG has come to be a text of persistent interest and relevance. Prior to his premature death in 1961, Maurice Merleau-Ponty devoted seminars to OG and produced an extensive amount of succinct notes, collected and summarized by Lawlor (2002a). Just a year after his death, Jacques Derrida (to my knowledge without participating in these seminars) published his first major work, a so-called "Introduction" to OG (Derrida, 1978 [1962]). Furthermore, OG's account of sedimentation has been influential outside the context of mid-20th century French phenomenology, as shown by commentators like Buckley (1992) and Woelert (2011). An even more recent application has been offered by Zlatev \& Blomberg (2016, 2019), where sedimentation is treated as an operative concept for outlining a dialectical relation between prelinguistic experiential motivations and conventional semantics. Interestingly, all these approaches build on different readings of OGs and they specifically diverge in their analysis of the concept of sedimentation. While they all emphasize how meaning is shaped and takes form against the backdrop of a linguistic-historical dimension, they move from this starting point in quite different directions. In light of this interpretative variation, my aim here is to present the main ideas in Husserl's text and to highlight the themes and issues that provide OG with its influence and recognition. To the best of my knowledge, this article is also the first attempt at comparing interpretations and further developments of the concept of sedimentation.

I begin in Section 2 with summarizing OG and placing it within the context of Husserl's phenomenology, specifically in relation to his mature thought, sometimes described as a "generative phenomenology" (Steinbock, 1995). Section 3 discusses two different but related readings of sedimentation, which both emphasize the relation between meaning as fundamentally rooted in embodied capacities, but differing in how they describe the way meaning detaches from these roots through language and other sign systems (Zlatev \& Blomberg, 2016, 2019) and habits (Woelert, 2011). Section 4 moves on to two interpretations that view sedimentation as indispensable for linguistic communication. While Buckley (1992) finds sedimentation to be a precondition for meaning to be linguistically transmitted in space and time, Derrida (1978 [1962]) radicalizes arguments found in OG to state that the potential endurance of written documentation serves as a requirement for ideal meaning. I conclude in Section 5 by teasing out decisive commonalities and differences between these interpretations, as well as offering some general comments on the conceptual issues at stake in OG and their relevance for thinking about the relationship between language and meaning.

\section{Sedimentation in Origin of Geometry: A recapitulation}

\subsection{From static to genetic phenomenology}

To fully appreciate the originality and complexity of OG, a bit of background on Husserl's thinking is required. In line with its partial heritage in Kantian philosophy, one of the important issues in Husserl's phenomenology is that of knowledge. Husserl insisted that knowledge even scientific knowledge - is in need of a secure foundation. In his early works, he attempted to find such a sturdy ground in the peculiar characteristics of consciousness that makes subjects different from objects (Husserl, 1970c [1900/1901]). In particular, consciousness can be 
characterized as being conscious of something. Phrased in phenomenological terms, consciousness is always intentional, that is directed towards something. Any type of object is thus always given in a particular way. As Husserl (1970c [1900/1901], p.95) writes, "in perception something is perceived, in imagination, something is imagined, in a statement something stated, in love something loved, in hate hated, in desire desired, etc.". Different types of such intentional acts all share the dative structure of being of something; one cannot just perceive in general without perceiving something. In turn, this shows that consciousness exhibits a correlative structure where intentional acts actively manifest objects - or constitute them, in a particular phenomenological sense. Importantly, the constituting abilities are not a matter of deliberation on the subject's behalf, but are rather an essential trait of consciousness itself. From such a perspective, Husserl (1983 [1913]) argued that a foundational epistemological level can be found in the constituting capacities of consciousness, making this transcendental, i.e. a pre-condition for knowledge and meaning.

As Husserl's thought developed, he came to recognize the limitations of an approach that only focuses on the constitution, or disclosure, of objects in intentional acts such as those described above. Prior to any such direct engagement, we are also always already affected by being a subject in the world. As bodily and worldly beings, we have certain dispositions and capacities through which we make sense of our surrounding world. These need not be intentional features in the sense of focally conscious judgments about object and their properties; rather, they are intentional in a broader experiential sense of a receptivity towards non-thematic and pre-reflective encounters with the surrounding world, which Merleau-Ponty (1968 [1964], p.37) will later describe as an "openness to the world". Already our bodily capacities display a kind of non-thematic engagement providing experience with meaning. Across Husserl's later writings, there are various observations on the human body as an indispensable precondition for intentionality. One such example is how the body displays a duality that in part relativizes the subject-object relation. This is shown when my left hand touches my right hand. I am then both an experiencing subject (through my left hand) and an experienced object (through my right hand). The relation, which Husserl (1989, p.152-154) refers to as "double-sensation" (Doppelempfindung), is not static and can at any time be reversed.

From such a viewpoint, which Husserl describes as "genetic phenomenology", the object of directed intentional experience is not something that comes ready-made to the constituting subject, but is rather something that forms in a historical process. This means that phenomenology should "follow [...] the necessary history of this objectivation and thereby the history of the object itself as the object of a possible knowledge" (Husserl, 2001 [1988], p. 634). We can thus distinguish this from the static phenomenology that studies the already "finished" products of sense-constituting acts (see Husserl, 2001 [1988], p. 624-634 for an instructive clarification of the difference between a static and a genetic phenomenology). ${ }^{2}$

As these genetic analyses continued and intensified, Husserl concluded that meaning is inextricably linked to having a world as the ultimate ground and horizon for experience. When we talk about the world in this sense, it should thereby not be taken as equivalent to the physical planet Earth or the universe that started with Big Bang; it is rather the experiential world that we perceive and act in, and which is usually "taken for granted" (Schutz \& Luckmann, 1973). Husserl calls this world where the sun goes up in the morning and down in the evening, and where there are other people, historical narratives and traditions, different cultures and norms the life world (Lebenswelt). The term is used in different senses in different contexts, covering both a pan-human, pre-predicative world of foundational experiential structures and a culturespecific world like "Europe". In both senses, the life world has phenomenological priority, which is why Husserl argues that abstract forms of knowledge like scientific worldviews also

\footnotetext{
${ }^{2}$ I use scare quotes around "finished" to indicate an important theme in phenomenology. Objects are given in perspectival "adumbrations" that do not principally exhaust an object (Husserl, 1983 [1913]). Therefore, constitution does not really have a fundamental end point where an object is fully and completely exhausted.
} 
depart from and are ultimately traceable back to the life world - even if they seem far removed from everyday human experience. They have their basis and attain their continued validity through a co-experienced and co-lived meaningful world, operating as the ultimate foundation for knowledge (Husserl, 1970a). At the same time, the move to the life world does not entail that the need for a ground for knowledge has diminished. Rather, the focus has shifted from consciousness as sense-constituting to its embeddedness within a world of actual and possible meanings.

\begin{abstract}
If Husserl's problem concerning the foundation of objective science was initially formulated as a problem concerning the foundational relationship between the scientific concept and the preconceptual intuition, in the course of his reflection it was transformed into the problem concerning the fundamental relation between the abstract world of objective theory and the concrete historical world of subjective life in which "theoretical praxis" belongs as one mode of human praxis among other. (Bernet, Kern \& Marbach, 1993, p. 222)
\end{abstract}

The life world is filled with various forms of culturally inherited traditions, such as the language we speak, the norms of our society, and so on (Zlatev \& Blomberg, 2019). Similar to how individual experience becomes sedimented into habitualized patterns, there is a culturally inherited constitution of historical sedimentations in the life world. While Husserl had been quite dismissive of the function history could serve in phenomenological analyses in his earlier work (e.g. Husserl, 1983 [1913]), he gradually accepted that we are inevitably situated within a history and as such we become "heirs of the past" (Ströker, 1984, p.196). This insight has profound consequences for phenomenology, as sense constitution is not just something that the subject does, but previously made acquisitions form a sedimented repertoire for further exploration. ${ }^{3}$ As argued throughout the remainder of this section, symbolic systems like language and scientific traditions can be seen as examples of such historically sedimented structures.

Before turning to OG, the attentive reader might have noticed that I have used the term 'sedimentation' to cover both the historical process spanning generations and the formation of habitualized patterns within an individual life. It is not fully clear whether these can be subsumed under one concept or should be treated as two distinct concepts. While they are encapsulated under a general concept by Moran \& Cohen (2012), I will focus only on sedimentation in the (generative) sense of a process that occurs in historical time. My reason for this choice is twofold: first, the interpretations discussed in Sections 3 and 4 are primarily concerned with such an understanding. Second, it makes the discussion more focused on language as a cultural-historical repository for knowledge, meaning and ideality.

\title{
2.2. Ideality rooted in the life world
}

As Husserl turns to the life world, he sometimes speaks of it as the "meaning-fundament" for theoretical knowledge (e.g. Husserl, 1970a, p.48). In OG, Husserl inquires into this fundament through a phenomenon said to be of "exemplary significance" (OG, p.353). This is the rational, deductive and axiomatic science concerned with ideal truths and pure forms: geometry. Even though exemplary, it is but one of many instances displaying the historical constitution of meaning and knowledge. With that said, geometry is chosen for being comprised of ideal objects that do not wither down and die, but instead remain invariably the same throughout time

\footnotetext{
${ }^{3}$ Whether these late texts comprise a complete break from Husserl's earlier works or if there is fundamental continuity is a question that has been discussed in the literature (e.g. Ströker, 1984). As far as I can tell, both positions have valid points and to a considerable extent depend on which parts of Husserl's thought are interrogated. For instance, Steinbock (1995) uses the term "generative phenomenology" specifically for a life world-oriented phenomenology concerned with phenomena generated in history and thus spanning generations (a dual meaning that Husserl also evokes).
} 
and are independent of the surrounding empirical conditions. Yet, to then conclude that ideality requires the existence of Platonic forms would be a phenomenologically invalid option, since it bypasses how such objects are constituted in experience and would therefore fall into mere speculation. As all knowledge, geometry must instead first and foremost be grounded in accomplishments of the subject, which means geometrical intuitions and the ability to abstract and idealize from physical shapes and forms. ${ }^{4}$ Husserl then poses a question about the relation between these intuitions and the ideality of geometry:

How does geometrical ideality (just like that of all sciences) proceed from its primary intrapersonal origin, where it is a structure within the conscious space of the first inventor's soul, to its ideal objectivity? (OG, p.358)

In line with his increasing interest in the historical becoming of the finished products of constitution, Husserl aims to answer this question by investigating the process through which geometry becomes established as a discipline, seemingly devoid of any connection back to the life world from which it must have originated. Maintaining that ideality both has an origin and is at the same time fundamentally supratemporal creates a tension whose importance cannot be overstated. It is evident that Husserl struggles with this throughout OG, and I will have reason to return to it on several occasions below.

Husserl (1970a [1936], 1970b) states that the forgetting of the life world characteristic of a modern scientific worldview entails a corresponding forgetfulness of the ultimate point of reference against which the legitimacy of knowledge is gauged. This is why the investigation into the phenomenological origins is so important: without it, we are at risk of losing the foundation that enabled knowledge to take root in the first place, and it will only live on in an impoverished form detached from the originally constitutive acts. Husserl sees the effects of such forgetting as detrimental: a science without ground, a forgetful naturalization and false neutralization of (inter)subjective participation indispensable even for the most objective kind of knowledge. The fear of losing contact with the origin should therefore not be mistaken for nostalgic lamenting, but concerns precisely the possibility of providing a ground for objectivity. With the link to the life world severed, the foundation of knowledge is at risk of becoming irrevocably lost. Husserl thus perceives the task set forth to be of crucial importance for human culture; even necessary in order to avoid a descent into nihilism, skepticism and relativism (Husserl, 1970a [1936]). As we shall see, the solution proposed to this philosophical (and moral) problem in OG is surprising, enigmatic, even slightly cryptic - especially so in relation to the general goals and aims of Husserl's phenomenological project. Arguably, these features also contribute to the variable interpretations of this text.

To begin tracing the origin of geometry, Husserl (1970a) takes inspiration from Herodotus and Aristotle, who speculatively claimed practices of land surveying to be the historical starting point for geometry. After the yearly flooding of the Nile, arable land had to be divided and measured in a way that ensured a correct redistribution. Reference to these practices, serving as a "meaning fundament", is sedimented in the etymology of the term 'geometry" ("measuring of land'). Of course, these practices also take place in a world that has some "invariant, essential structures" (OG, p.375), like the fact that it is comprised of "bodies" of various shapes, forms and materials.

What is also clear, and can be secured at least in its essential nucleus through careful a priori explication, is that these pure bodies had spatio-temporal shapes and 'material'

\footnotetext{
${ }^{4}$ In some crucial respects, this process of abstraction and idealization remains somewhat implied in OG (Derrida, 1978 [1962], p.102). Elsewhere, Husserl distinguishes the "free" ideality of geometrical forms from the "bound" ideality of physical shapes and forms like 'round' (Husserl, 1973 [1948], p.267). In the latter case, ideality is still connected to actually physical shapes whereas free idealities have severed this link and deal only with pure forms.
} 
[stoffliche] qualities (color, warmth, weight, hardness, etc.) related to them. Further, it is clear that in the life of practical needs certain particularizations of shape stood out and that a technical praxis always aimed at the production of particular preferred shapes and the improvement of them according to certain directions of gradualness. (OG, p.375)

In this quote, Husserl expresses a decisive point for undertaking the generativephenomenological endeavor. Given that ideal meaning is an achievement that emerges in the life world, the various genetic sources for the establishment of geometry are not a mere recapitulation of empirical factors which could just as well have been otherwise, but are part of the transcendental conditions indispensable for the possibility of geometrical ideality. This is one of the most important and decidedly difficult aspects of OG. To see Husserl's account as a historical description would reduce it to an inquiry into a history of geometry. Similarly, it would be equally reductive to seek the origin in a hypothetical psychological genesis of what it would have been like for Pythagoras, Euclid or any other early geometer. Instead, when Husserl seeks the phenomenological origin of geometry in lived experience, it should be seen as the preconditions for its establishment as a tradition. Without this, we would not even know what geometry is or could be like.

\subsection{Language, ideality, sedimentation}

Even though Husserl sees geometry as growing out of non-geometrical practices, he also wants to maintain ideality as devoid of any connection back to the processes that led to its establishment. Independent of its genesis, the Pythagorean theorem can be used to perform calculations valid for all right triangles. We know how to calculate the area of a circle without going through the entire historical process that led to Euclidean geometry. Once created and established, the formula for calculating the area of a circle is $\pi r^{2}$, which will remain exactly the same on all subsequent uses. The formula has broken off from the history that produced it in the first place and exists ever since independently of it.

As Husserl analyzes this, the ideal space of geometry has been separated from the source that allowed it to emerge in the first place. It lives on as calculation. As a characteristic feature of modern science, this means a form of understanding based on symbolic notation thrown back onto the life world from which it originated. Such a shift in attitude leads to an arithmetization of nature and thereby to a loss of the origin that endowed natural science with meaning in the first place (Husserl, 1970a, pp.23-59). ${ }^{5}$ In this process of idealization, Husserl notes a momentous shift in the semiotic properties of the representational means. Geometry becomes ideal by establishing a notation where the symbols are "emptied of meaning" in the sense that the symbols no longer involve reference to anything within the life world (Husserl, 1970a, pp. 46-48). ${ }^{6}$ Instead, they have achieved such a considerable degree of abstraction that there is no apparent link to whatever experience endowed them with meaning in the first place. Here we find an articulation of the conundrum that Husserl is tackling: on the one hand, the phenomenological-transcendental foundation in the life world and on the other, the ideal forms of geometry remaining irreducible to their historical becoming. We can then return to the question posed at the end of Section 2.2: how can ideal forms detach from their origins and establish a tradition of ideality? The answer suggested in OG is that geometry is guaranteed through linguistic forms, and specifically through the permanence and endurance of writing.

To appreciate why such an emphasis is put on language, it is important to recall the close relation between language, world and meaning articulated in OG. Two related claims are made

\footnotetext{
${ }^{5}$ There are some striking similarities between Husserl's (1970a) diagnosis of the crisis in Western civilization and Heidegger's (1962 [1927]) view on the "forgetfulness of being". Exactly how to spell out the connection is a matter of debate in the literature (e.g. Buckley, 1992; Lawlor, 2002a).

${ }^{6}$ See Duke \& Woelert (2016) for an instructive discussion on the role of numbers and other mathematical symbols in the genetic constitution of ideal objects.
} 
regarding this connection. First, the life world is to a considerable extent intersubjectively shared through language, which has the ability to name everything. It is against this background that language has the potential for sense to be transmitted beyond the immediate here and now, thereby opening up an endless horizon of civilization, depositing what can be commonly known and shared.

Clearly it is only through language and its far-reaching documentations, as possible communications, that the horizon of civilization can be an open and endless one, as it always is for men. (OG, p.358)

Language, for its part [...] is related correlatively to the world, the universe of objects which is linguistically expressible in its being and its being-such. Thus, humans as humans, fellow humans, world - the world of which humans, of which we always talk and can talk - and on the other hand, language, are inseparably intertwined [verflochten] (OG, p.359)

As I interpret these passages, the very possibility of having a world as a culturally, historically and intersubjectively constituted phenomenon requires language. Husserl is apparently proposing that the openness of the life world as a dynamic horizon for human activity involves "the far-reaching documentations" of language, not only for communication but also for constituting this human life world in terms of providing an intersubjective common ground and for continuously ongoing explorations into its nature.

Husserl's second reason for the importance of language points to a formal similarity between the stability of linguistic forms and ideality. An outstanding trait of the ideal is to always remain the same across possibly infinite repetitions and uses. Husserl claims that this is also a trait of linguistic items, given that a word is the same on every repetition: "language itself [....] is thoroughly made up of ideal objects [...] the word Löwe occurs only once in German" (OG, p.357). On the view that Husserl proposes, the sense of a linguistic item remains intact over repetitions, while at the same time repeatability without erosion and loss of sense is also a trait of ideal objectivity. Even though the ideality of geometrical truths and the ideality of language are fundamentally different in kind, Husserl still sees language as indispensable for the possibility of ideal objectivity. Specifically, he claims that it is in written form that ideality "receives its linguistic living body" [Sprachleib] (OG, p.358), through which ideal objectivity can be shared, handed down, elaborated, sent, delivered and remembered across generations. In order for ideality to be deposited within the world, it thus has to be documented in a form that can survive the death of actual subjects. In contrast to the practices of actual scientists and philosophers, ideality is unaffected by the passing of time. To be absolutely ideal "the object must be freed from actual subjectivity, freed from actual evidence for a subject and freed from actual circulation within a determinate community" (Lawlor, 2002b, p.116). To ensure this, it is specifically the endurance of written documentation that guarantees the transmission of a univocal meaning. Discussing the need for such external representations, Husserl writes:

\footnotetext{
Now we must note that the objectivity of the ideal structure has not yet been fully constituted through such an actual transferring of what has been originally produced in one to others who originally reproduce it. What is lacking is the persisting existence of the 'ideal objects' even during periods in which the inventor and his fellows are no longer wakefully so connected or even who are no longer alive. What is lacking is their continuing-to-be even when no one has realized them in self-evidence. The important function of written, documenting linguistic expression is that it makes communications possible without immediate or mediate personal address; it is, so to speak, communication become virtual. (OG, p.360-361)
}

Were it not for the virtual communication made possible by "written documenting linguistic expression", geometry would thus never leave the confines of face-to-face communication between "the inventor and his fellows". Through history and as a culturally formed tradition, 
science has progressed further and further, but this progress also buries and conceals the origin under strata fashioned by history.

It is by now finally time to familiarize ourselves with the central concept Husserl uses for describing this dialectical process: sedimentation, understood as the historical formation of stable meaning structures that are received, manipulated and communicated further without any necessary link to how these forms originated. The use of this geological term is by no means an accident, but deliberately plays on the way a structure in the present is established through a historically dynamic process, as clearly summarized by Woelert (2011, p.119):

\begin{abstract}
Sedimentation, in spatial terms, describes a process whereby particles collect together and build vertically. This vertical process, in turn, leads to the establishment of horizontal strata that over time form a stable structural configuration. Thus, sedimentation not only combines structure and process, spatial order and becoming, but also two spatial movements that on the face of it are mutually exclusive: particles sediment in a downward movement, leading to the formation of stratified configurations that grow from the bottom upward.
\end{abstract}

At the same time, Husserl points out dangers that follow from the process of sedimentation, with the resources in language, notations and scientific theories as seducing and luring us astray from an authentic meaning. Over time, representations in written language and symbolic notation replace the original sense they were supposed to convey. To be wholly within these acquired forms therefore "remains a constant danger" (OG, p.362). As was mentioned earlier, it permits the total detachment from the originary acts and thus allows for a science without phenomenological ground. Preserved in such forms, knowledge is jeopardized by the severed link to the (generative) constitution of ideal meaning. We are faced with a "passive taking-over of ontic validity" (OG, p.364) and the "seduction of language" (OG, p.362). The drawback is thus a forgetfulness of the original experiences that endowed the handed-down forms of any established science (including all features of scientific theory, like rigid nomenclature, diagrams, and symbolic notation) with sense in the first place.

To overcome the danger of such extreme passivity, Husserl urges for the need of a phenomenological reactivation of the original sense that imbued a science like geometry with meaning in the first place. This is carried out by digging through the sediments to disclose the self-evidence in which it must have been given "for the first time". It is in the disclosure of this meaning origin that a phenomenological method becomes indispensable. To find the origin of sense as it must have appeared requires an arduous process of digging through the sedimented layers fashioned by history. Husserl calls such a phenomenological analysis for a "returninquiry" (Rückfrage) where the passivity of language can be removed and the link back to the (phenomenological) origin can once and for all be secured. Ideality would then survive in a form that does not exclude remembering the originary meaning. Once retained, its meaning could then be transmitted across generations and would be translatable with minimal or even no loss or change in meaning.

\title{
2.4. A few reservations on language
}

To conclude this section, and before proceeding on to the various interpretations of the concept of sedimentation, a few words of caution are warranted. When Husserl states that geometry must survive in a format external to (but comprehensible by) human beings, it important to maintain the distinction between the ideality of the geometrical objects themselves and the "idealities of geometrical words, sentences, theories - considered purely as linguistic structures" (OG, p.357), as mentioned above. While we use various figures and symbols in geometry, these are representations of "ideal figures as scientific objects" and not the ideal objects themselves (Noe, 1992, p.124). An instructive way to clarify the difference between linguistic and geometric invariance could be to distinguish between various forms of idealities not explicitly 
separated from one another in OG, but nevertheless presupposing distinctions made by Husserl elsewhere (e.g. Husserl, 1970c [1900/1901]; cf. Derrida, 1978 [1962], p.70).

One type is what could be called identity of expression, the notion that a linguistic sign remains identifiable as "the same" across its usages (comparable to the distinction between word type and word token). This identity does, however, remain relative to a particular speech community and thereby still remains "tied to real spatiotemporality" (Derrida, 1978 [1962], p.70). We can then compare the German word Löwe to its English counterpart lion. While they are different words, they still coincide in having the same content intended from the perspective of different languages. This second form of ideality is a matter of identity of content, which in turn should be separated in the context of geometry from the ideality of objectivity, which remains invariably the same independently of any language or other semiotic system. ${ }^{7}$

The Pythagorean theorem, [indeed] all of geometry, exists only once, no matter how often or even in what language it may be expressed. It is identically the same in the 'original language' of Euclid and in all 'translations'; and within each language it is again the same, no matter how many times it has been sensibly uttered, from the original expression and writing-down to the innumerable oral utterances or written and other documentations. (OG, p.357)

The difference between these idealities can be further illuminated by the distinction between bound and free ideality (see fn. 4). Identity of expression is bound to an actually existing speech community, whereas the ideality of objectivity is free from any empirical influence (see Derrida, 1978 [1962], pp.71-73). While these are conceptually distinct kinds of idealities, what is at stake in OG is how a tradition of ideality can be achieved within the finitude of the life world. As we have seen, this is an achievement that happens through the relative permanence and stability of linguistic meaning, which allows for "ideality and historicity to come together" (Noe, 1992, p.124). On the point of how and in what way language contributes to achieves this, Husserl is far from clear, but it seems to involve at least the following different features:

a. Language as a collective and intersubjectively established system allowing for communication.

b. The stabilization of meaning in linguistic form as a constantly ongoing communal process of elaborations and specifications.

c. Written documentation as allowing for the conventional establishment and preservation of a stable meaning.

d. The stable, defined and technical terminology of scientific theories where the signs have attained a high degree of objectivity (with the consequence that they been "emptied" of the sense that endowed them with meaning in the first place).

The exact individual contributions of (a)-(d) for the process of sedimentation remains unspecified in OG. Whereas Derrida's reading discussed in Section 4 focuses specifically on (c) and (d), the additional three interpretations, discussed in Section 3 and 4, focus on (a) and (b), but do so in different ways. Arguably, this variation regarding the ways in which properties of language affect sedimentation contribute to the distinctive characteristics of each interpretation.

In sum, I have attempted to summarize OG in a way that remains sensitive to its issues and to point out its compelling and intriguing ideas concerning the irreducibility of stable meaning structures while still retaining that they originate from dynamic activity. In brief, Husserl argues that the phenomenological origin of ideal objectivity must paradoxically be forgotten in order for it to operate as ideal. At the same time, it is this forgetfulness of origin

\footnotetext{
${ }^{7}$ What I refer to here as identity of expression, identity of content and ideal objectivity corresponds to Derrida's tripartite division between primary, secondary and tertiary ideality (Derrida, 1978 [1962]).
} 
that has placed modernity in a crisis. By allowing for a passive reception of meaning in language, and specifically in the form of writing, it serves as a main contributing factor to this forgetfulness. In glaring opposition to this, Husserl is also proposing that language and written documentation are indispensable in establishing a philosophical or a scientific tradition in the first place. ${ }^{8}$ This somewhat paradoxical duality of sedimentation is something that requires further attention.

\section{Zlatev \& Blomberg, and Woelert: From experience to language (and back again)}

The relation between pre-linguistic and linguistic meaning in central for the approach proposed by Zlatev \& Blomberg (2016). Their analysis of various constructions in human languages suggests that linguistic meaning is motivated from pre-linguistic and fundamentally intersubjective bodily experiences, like the double-sensation of the body (see Section 2.1) and that of the perception of affordances. Over time, such experiences give rise to particular (linguistic) signs, which become conventionalized and stabilized. This means that language users do not have to "go back" to a founding moment or truly relive the experience that motivated the sign use in the first place. Building on this basic idea, Zlatev \& Blomberg (2019) formulate a general semiotic model, the Motivation \& Sedimentation Model (MSM), ${ }^{9}$ which claims that meaning making presupposes the interaction between three interrelated levels: (a) the Embodied level of experientially rich and intersubjectively shared embodied structures, which motivate (b) the Situated level language use (or other kinds of sign use, like gesturing) which over time sediments into (c) the Sedimented level of conventional stable and more schematic meanings of particular sign systems. In other words, there was an originary moment where a sign was used for the first time on the Situated level, as motivated by the Embodied level. If this act is communicatively successful, it might lead to the continued use of this sign with this particular meaning. Over time, the origin will become sedimented and the expression can continue to function in the absence of knowledge of the motivation. For this model, the central role of sedimentation is thereby to show how historical processes operate to both establish and extend the meaning of linguistic and non-linguistic signs.

This may be illustrated by the use of motion expressions to describe static extended entities, like those on (1) and (2).

(1) The road goes through the forest.

(2) The mountain stretches all the way to the sea.

Such sentences of non-actual motion may be analyzed as motivated by three distinct types of bodily experiences connected to motion: (a) motion affordances of particular objects like roads, (b) the motility of (visual) perception in relation to an elongated object and (c) the imagination of the static object moving. Of course, when we use expressions like (1) and (2), these motivations are not immediately apparent. This is so because they have become sedimented over time and are no longer needed in order to use and comprehend non-actual motion sentences as the conventional way to describe spatial extensions in English and many other languages. As stated by Blomberg \& Zlatev (2014, p.416):

\footnotetext{
${ }^{8}$ One reviewer correctly points out that scientific traditions do not necessarily need to be preserved in written form. According to Foley (1997), India did not develop a stable tradition of written records before the 16th century. This is predated with ca. 2000 years by Panini's grammatical analysis of Sanskrit, which was both formulated and transmitted mainly as an oral tradition (Itkonen, 1991)

${ }^{9}$ See also Stampoulidis, Bolognesi \& Zlatev (2019) and Devylder \& Zlatev (2020), where MSM is applied to metaphors in language and depiction.
} 
Experiential motivations can be viewed as sedimented through 'passive' processes of acquisition and social transmission, and that this implies an interactive loop between experience and language, yielding losses in terms of original experience, but gains in terms of communal signification.

By focusing on the socially shared character of language (and other sign systems) as allowing for transmission of meaning without any need to return to the presumed foundational motivating experiences, this use of the concept of sedimentation echoes Husserl's view in OC. In contrast, however, sedimentation in MSM does not necessitate a destructive process, since the experiences in the Embodied level do not disappear, and can always be re-activated. The Sedimented level is required for language as a conventional sign system to operate, since communicative function would collapse if the original motivations of words' meaning had to be retained and brought to life at every mention. Still, such motivations are always (potentially) present as deeper level of meaningfulness, which allows creative use and change of the system.

An interpretation similar in its emphasis on pre-predicative experience and bodily capacities is that of Woelert (2011). Instead of connecting these to sedimentation in language, it is more concerned with a theme in Husserl's genetic phenomenology: the roots of abstract thinking in more basic forms of experiences. Woelert's analysis departs from the observation that conceptual frameworks tend to use terms with a sedimented reference to space. This can be found in the etymology of many technical, scientific and philosophical terms, like hypothesis ('under' + 'to place'). Fundamental conceptual oppositions like inner/outer or theoretical notions like foundation can similarly be analyzed as involving a latent connection to spatial meaning. Even in their conventional sense, these terms can be seen as originally recruiting their meaning from embodied spatial experience - a point also extensively discussed by Lakoff \& Johnson's $(1980,1999)$ Conceptual Metaphor Theory. Woelert analyzes such terms as a sedimented repertoire of stabilizing structures that function as a superindividual memory, based on processes of habituation and conventionalization. This off-loading is typically made into linguistic or symbolic forms, but it is interesting to note that sedimentation on this reading also includes established patterns of spatial organization and the use of non-linguistic materials in the environment (Woelert, 2011, p.120).

While sedimented terms and habits no longer necessarily have an active reference to spatial experience, they nevertheless serve as a guide that leads thinking along certain established pathways. As is typical for the notion of sedimentation, there is the familiar ambivalent duality that comes about through this process. For Woelert, the habitualization of certain possibilities provides "a cognitive scaffold that liberates the thinking of the human individual from the impossible task of thinking everything simultaneously and constantly anew" (Woelert, 2011, p.120). By virtue of being such a cognitively efficient tool for thinking, the origin of this "cognitive scaffold" in particular conceptions of spatial experience becomes unquestioned.

On the one hand, they exert a stabilizing yet restrictive force as they subliminally guide human thought down well-established avenues and anticipate certain connections and associations. On the other hand, it is these same structures and the restrictions they impose that make possible the process, and progress, of human conceptual thinking, including the possibility of new bifurcations and perspectives. (Woelert, 2011, p.123)

In other words, abstract thinking is based on the sedimented structures from pre-predicative spatial experience, which forms a stable structure for further conceptual activity that in turn leads to developments and hence even more sedimented layers. These structures are - as Woelert emphasizes - not formed from a completely neutral perspective but are based on particular conceptualizations of spatial experience that over time conceal that they are derived from space. Since even abstract thinking has a spatialized point of departure, it limits the possibilities to get out of such a perspective. When we turn towards understanding how abstract 
thinking is possible, we have to rely on the same structures to understand it. This is why Woelert (2008) points to the indications of such a fundamental spatiality in phenomenological terminology as well, with examples like ground and horizon; or the phenomenological perspective as re-orientation (Husserl, 1970a, p.18). In sum, progress, developments and advancements are simultaneously made possible and restricted by sedimentation.

Despite a number of similarities, there is one striking difference between the two interpretations discussed in this section. While they both agree on the foundational role of embodied experience, they differ in "where" sedimentation operates. For Zlatev \& Blomberg it is a matter of linguistic (and other semiotic) meaning structures that sediment particular experiential processes. Woelert, on the other hand, sees sedimentation as offering a conceptual and cognitive repertoire that includes abstract thinking in general. This is why he can claim that sedimentation "ought not to be regarded as a detrimental process, i.e., as a hollowing or emptying of thought [...] but as an essential condition of the possibility of constructive human thinking" (Woelert, 2011, p.120). Even though they differ in this regard, the interpretations are still in important respects compatible, and could possibly even complement one another. Both are concerned with the complex interweaving movement of sedimentation as the emergence of a stable meaning structure on the basis of a dynamic diachronic processes, which entails a gradual movement away from the roots in bodily experience. Woelert's account explicates how the process of sedimentation both retains and moves away from its roots in pre-predicative experience. Zlatev \& Blomberg, and MSM more generally, provide a fleshed-out account of how specific structures of bodily experience underlie both the use, and the conventionalization of language and other sign systems.

\section{Buckley and Derrida: Sedimentation as an essential drift away from the origin}

While the previous section was concerned with sedimentation as a process that builds on prelinguistic meaning, this section touches on two readings of $O G$ that differ by seeing sedimentation as a necessary condition for meaning to be communicable beyond a here and now. The first of these is Buckley's (1992) analysis of sedimentation as intricately linked to the possibility for linguistic communication. Linguistic meaning has a historical dimension, which means that we do not have to find new expressions but can rely on conventional and already existing forms that we can expect others to also know. In doing so, we are operating at the "surface" without reactivating the entire chain that gave birth to the sign in the first place. A linguistic sign is therefore breaking off from its original meaning in such a way that we become free "to engage in new productive expressions" (Buckley, 1992, p.91), sometimes bending and going beyond existing language. This interplay is what Buckley $(1992, p .90)$ refers to as the "paradoxical elasticity" of language.

Buckley claims that this break from the origin is a necessary precondition for linguistic communication to be possible in the first place. As also emphasized by Husserl, language both preserves an original meaning and breaks away from it. Following this logic to its end, but also moving away from Husserl's view on sedimentation, Buckley proposes that sedimentation is not just an empirical accident that follows from an inauthentic or passive reception, but a condition for sense to be linguistically communicated beyond an immediate presence. While the effects of sedimentation might become evident first in hindsight through historical processes, this is but a surface manifestation of a much more profound function that sedimentation has for linguistic communication. That is, the general applicability of the same linguistic signs - their identity of expression and ideality of content - presupposes that they are not limited to a specific here and now. Even if there was a first place and first time that imbued a word with meaning, this moment is after the fact no longer required for its sustenance which also makes it incapable to regulate how it will be received and further transmitted. Sedimentation is thereby not just a historical process but a precondition for any kind of linguistic meaning to be possible. 
The elasticity of language is related to some well-established ways of looking at linguistic meaning, like the oppositions between convention and use, or between semantics and pragmatics. These are meant to show that the conventionally established sense is never sufficient to capture the nuances of any particular use. Moreover, sense is not rigorously regulated to the extent that no uses can deviate from this norm. Arguably, such uses are a component that drives semantic change in the history of a language. While Buckley's account does resemble these oppositions, it is also important to note what is specifically at stake with sedimentation: the duality of sense constitution where an original meaning is both indispensable but also necessarily involves a movement away from this origin. While such a duality is different from dichotomies like convention/use or semantics/pragmatics, it could perhaps be seen as an account for why such dichotomies appear in the first place.

The last interpretation to be discussed is also chronologically the oldest, presented in Derrida's somewhat misleadingly titled "Introduction" (given that it is about 10 times the length of Husserl's text, this title should perhaps be understood ironically). In this text, themes from OG are radicalized to propose that writing and ideality share an immediate bond. I discuss this reading of the concept of sedimentation last in this paper not only because Derrida goes most indepth with the source material, but also because he offers the most convoluted and complex reading of the four interpretations. ${ }^{10}$

In Section 2.4, I made a differentiation between four different aspects of language (a-d). Of specific relevance for Derrida's concerns, as pointed out, are those connecting the written form to the preservation and stabilization of meaning, (c) and (d). At the same time as written representation may be said to preserve ideal meaning, it also forms a deceiving system where meanings are conjured up without the demand for retaining a rigid connection to their phenomenological origin. For Derrida, this highlights two opposing facets specific to written language of any form. On the one hand, linguistic communication occurs in a system beyond individual control. To address an absent other person in writing, as I am doing right now, involves a latent risk. I might be incomprehensible, or a reader might unintentionally - or deliberately - misinterpret me. This risk is always involved when sense in transmitted in factual communication. Thus, the originary, univocal meaning is constantly at risk of being lost or to be just one of many different senses. On the other hand, we can go back to Buckley's interpretation to see that language allows for transmission without going back to the origin or founding moment. Of course, this is in line also with OG, where Husserl writes that science could not progress if we had to "run through the whole immense chain of groundings back to the original premises and actually reactivate the whole thing" (OG: 363). This is why language and symbolic notation is seen by Derrida as required for ideality to be transmitted across space and time.

This tension of written language as simultaneous bondage and liberation of truth is what Derrida (1978 [1962], pp. 69-70) calls "the most difficult problem [of Origin]". From this we can find two important points in Derrida's interpretation: a radicalization of the notion of writing and and a criticism of how Husserl treats writing. These depart from admissions found in OG, such as the importance of writing for ideality and repeatability as the trait of identical sense. Written forms can have the stable and permanent meaning required for transgressing the empirical limitation of factual persons. Derrida reads this as claiming that (transcendental) consciousness cannot constitute ideality by itself. Instead, it must be supplemented by something that can preserve meaning even when any subject perishes. This supplement is not just an empirical creation in order to communicate ideality; rather, it has to be already there for the phenomenological subject to attain some of its constitutive abilities. Derrida states that "[b]y virtualizing dialogue, writing creates a kind of autonomous transcendental field from which every actual subject can be absent" (Derrida, 1978 [1962], p.88). In this sense, writing is no longer mainly a way to communicate through exterior representations, but attains a much more

\footnotetext{
${ }^{10}$ With that said, I am still not convinced that I have managed to do justice to Derrida's interpretation. Doing so would probably require yet another introduction about ten times the length of his introduction!
} 
integral role in the generative formation of sense as "the highest form of constitution" (Derrida, 1978 [1962], p.89). In this radicalization of OG, ideality presupposes writing, which in later works will make Derrida (1976, [1967]) refer to writing in such an extended sense as a "necessary supplement" and as "ultra-transcendental". That is, transcendental subjectivity is unable to constitute ideal objects without the help of writing in this extended sense.

This takes us to the second point: the criticism Derrida directs towards Husserl's project. A natural human language cannot guarantee the pure preservation of ideal objectivity for Husserl. This is indeed an important precondition for the crisis, which is why Husserl strives for a language that minimizes ambiguity through a responsible and honest communal effort (OG, pp.362-373). Without denying the possibility that this is possible in principle, Derrida still questions whether it is empirically plausible to ensure that even the most theoretically wellfounded scientific terminology can retain exactly the same meaning across all repetitions. As we have seen, ideality requires indefinite repeatability without change in meaning. However, there is always a latent risk that some repetitions cause disturbances (Derrida, 1978 [1962], p.106). It is like the game of Chinese whispers: it takes just one erroneous transmission for the word to lose the sense it was supposed to convey, or for it to gain additional senses. This is why Derrida states that no language in any form can uphold the rigorous criteria for a permanent and stable meaning.

\begin{abstract}
If equivocity is always irreducible, this is because words and language in general are not and can never be absolute objects. They do not possess any resistant and permanent identity that is absolutely their own [...] The 'same' word is always 'other' according to the different intentional acts which thereby make a word significative. (Derrida, 1978 [1962], p.104; citation slightly modified)
\end{abstract}

This takes us back to Section 2.3 where we saw that Husserl argued for the ideality of linguistic forms. Derrida is here objecting to analyzing words as having the same type of permanence as ideal objects do. Instead, a completely different view on linguistic meaning is hinted at: the identity of expression must also take into account that each use gets its meaning from distinct and different intentional acts. This interplay between sameness and difference is also something that will become important in Derrida's later work.

Let me now summarize this section by pointing out a few decisive similarities between Buckley's and Derrida's readings of OG. By stating that the original meaning need not be recoverable, they run counter to Husserl's view of sedimentation and the two interpretations discussed in Section 3. Instead, they both emphasize how sedimentation entails a formal separation between language and whatever type of experience is supposed to be communicated. Once sense takes linguistic form, there is a rift between language and its motivating forces that also seems to render the latter somewhat irrelevant. On Buckley's analysis, the communicative needs of linguistic meaning drive the process of sedimentation. For a linguistic sign to recur at another time and place, it cannot be applicable only to a particular situation but must abstract away from it in a way that lets it be reusable at any time. How language retains meaning is however not further specified by Buckley beyond stating that language is "paradoxically elastic".

A similar way of thinking is found when Derrida (1978 [1962], p.118) states that "creation which discloses and sedimentation which covers over imply each other". Writing institutes ideal sense and is in this way what allows the origin to be remembered and inscribed as just an origin. At the same time, the linguistic form also risks obliterating the originary meaning. For Derrida this must be read in a completely different way than for Husserl, however: if the stability of linguistic forms is required for ideality to be instituted, then sedimentation has always already been at work. It is not something that befalls an origin uncontaminated by the complexities of language. Since this reading sees Husserl as saying that linguistic form is required for ideality, it implies that the crisis was inaugurated already at the origin. Followed through to its end, the preservation of the origin conceptually paradoxically requires the 
potentiality of its own destruction. This is how Derrida analyzes the "logic", or in his terms, the "graphics" of the origin.

\section{Conclusion}

Husserl had the remarkable ability to relentlessly keep digging deeper and deeper through the hardened and solidified crusts covering the vibrant structures of human experience. His philosophy was never content with finding an intellectually comfortable place where everything appears as neat and tidy. Instead, he persistently continued on, even to the point of undoing what he had established in previous investigations. This attitude is evident all the way up to the last texts, which is why Merleau-Ponty (1964 [1960], p.160) notes in The Philosopher and His Shadow that "[a]t the end of Husserl's life there is an unthought-of element in his works which is wholly his and yet opens out on something else". As Lawlor (2002a) interprets this passage, it seems to imply that Husserl's death was required to open up for this unthought-of. This is a truly fitting heritage for Origin of Geometry. The written document is in a sense "dead": it is, as Merleau-Ponty describes it, "a monument" (Lawlor 2002a). As such, it has become the subject of multiple readings and interpretations - even to the extent that the effects of sedimentation have befallen the text of OG itself.

The main purpose of this paper was to de-sediment the concept of sedimentation by going back to Husserl's original text. To further elucidate this concept, I looked at four interpretations of OG that end up treating sedimentation in quite different ways. While this speaks to OG's richness, it also highlights the tensions within the text. Specifically, Husserl states that language fixates sense in a stable way that allows it to be communicated across space and time. When it comes to how indispensable this is for sense constitution, OG expresses a hesitant ambivalence that is clearly reflected in the different themes and interpretations discussed in this paper. On the one hand, it emphasizes the necessity of a link between founding experiences and the sedimented structures built on these experiences. Were it not for such experiences, nothing would get sedimented in the first place and no phenomenological origin could be retrieved. On the other hand, one can also read Husserl as advocating a radically different conclusion: an original meaning can neither survive nor make way for stable structures without being deposited in linguistic (or other semiotic) form. The possibility of ideality hinges on the embodiment of sense in a communally available external form. This has a further consequence following from the shift to supratemporal impersonal meaning: written documentation is not bound to anyone. Such a reading of OG that emphasizes the connection between ideality and the endurance of external representations is most explicitly endorsed by Derrida's interpretation. Written documentation does not amount to a substitute for face-to-face communication or a mnemonic technology, but serves as a necessary supplement for the constitution of ideal objectivity.

It seems safe to say that the connection between sedimented meaning and its phenomenological origin is one of the core issues where the four interpretations display their most pronounced differences. Both Woelert and Zlatev \& Blomberg point to the structuring and motivating function of embodied experiences. Buckley differs by stating that sedimentation makes linguistic meaning fundamentally drift away from its origin. In a similar way, Derrida sees sedimentation as a complex interweaving between origin and its preservation in written form through which their relation to one another has to be rethought. Despite these differences, all four interpretations appear to read the concept of sedimentation in a more constructive and positive way than Husserl did. Just as Buckley, Zlatev \& Blomberg emphasize the intricate connection between the possibility of linguistic meaning and sedimentation. They agree that language requires an essential drift away from the originary experiences that imbued it with meaning in the first place. Woelert takes this even further by considering conceptual frameworks as by and large requiring a sedimented repertoire that lets conceptual activity continue on from previous acquisitions, without having to think everything anew all the time. 
Finally, Derrida argues that the endurance and stability offered by the materiality of writing is required for the constitution of ideality.

In sum, I hope to have shown how OG in a remarkable way shows the complex relationship between meaning and the (linguistic) resources for representing it. It shows how a fundamental conceptual opposition between pre-predicative experience and language can be retained, but how this still leaves room for investigating their joint historically constituted interdependence. The concept of sedimentation implies a strange and sometimes even paradoxical logic that also binds preservation to forgetfulness, and even the ideal to the worldly. In this way, Husserl finds a way for thinking about such mutual dependencies without reducing one to the other, and has influenced generations of thinkers along this path.

\section{Acknowledgments}

I am lucky to have such a smart and good friend as John Haglund. His insightful comments on several drafts of this paper were immensely helpful. I am grateful for the editorial suggestions from Jordan Zlatev and Georgios Stampoulidis, which turned this into a much more structured and coherent paper. Finally, the critical feedback from three anonymous reviewers provided comments, objections and suggestions that really forced me to go back and re-think my reading of Husserl.

\section{References}

Bernet, R. Kern, I. \& Marbach, E. (1993). Introduction to Husserlian phenomenology. Evanston: Northwestern University Press.

Blomberg, J. \& Zlatev, J. (2014). Actual and non-actual motion: why experientialist semantics needs phenomenology (and vice versa). Phenomenology and the Cognitive Sciences 13(3): 395-418.

Buckley, R. P. (1992). Husserl, Heidegger and the crisis of philosophical responsibility. Dortrecht: Kluwer.

Derrida, J. (1976 [1967]). Of grammatology. (Trans. G. C. Spivak). Baltimore and London: The Johns Hopkins University Press.

Derrida, J. (1978 [1962]). Edmund Husserl's Origin of geometry: An introduction. (Trans. J.P. Leavey, Jr). Lincoln and London: University of Nebraska Press.

Derrida, J. (2003 [1990]). The problem of genesis in Husserl's philosophy. Chicago and London: University of Chicago Press.

Devylder, S. \& Zlatev, J. (2020). Cutting and breaking metaphors of the self and the Motivation and Sedimentation Model. In A. Baicchi (ed.), Figurative meaning construction in thought and language (pp. 254-281). Amsterdam: Benjamins.

Duke, G. \& Woelert, P. (2016). Husserl and the problem of abstract objects. Pacific Philosophical Quarterly 97: 27-47.

Foley, W. A. (1997). Anthropological linguistics: An introduction. Oxford: Wiley-Blackwell

Heidegger, M. (1962 [1927]). Being and time. (Trans. J. Macquariie and E. Robinson). London: SCM Press.

Husserl, E. (1970a [1936]). The crisis of European sciences and transcendental phenomenology. An introduction to phenomenological philosophy. (Trans. D. Carr). Evanston: Northwestern University Press.

Husserl, E. (1970b). Origin of Geometry. (Trans. D. Carr). In Husserl (1970a).

Husserl, E. (1970c [1900/1901]). Logical investigations. (Trans. N. J. Findlay). London: Routledge \& Kegan Paul.

Husserl, E. (1973 [1948]). Experience and judgment. (Trans. J. S. Churchhill and K. Ameriks). London: Routledge \& Kegan Paul. 
Husserl, E. (1983, [1913]). Ideas pertaining to a pure phenomenology and to a phenomenological philosophy. First book. (Trans. F. Kersten). The Hague: Martinus Nijhoff Publishers.

Husserl, E. (1989). Ideas pertaining to a pure phenomenology and to a phenomenological philosophy. Second book. (Trans. R. Rojcewicz and A. Shuwer). Dortrecht: Kluwer Academic Publishers.

Husserl, E. (2001 [1988]). Analyses concerning active and passive synthesis. Edited by A. J. Steinbock. Dortrecht: Springer.

Itkonen, E. (1991). Universal history of linguistics: India, China, Arabia, Europe. Amsterdam: John Benjamins.

Lakoff, G. \& Johnson, M. (1980). Metaphors we live by. Chicago and London: University of Chicago Press.

Lakoff, G. \& Johnson, M. (1999). Philosophy in the flesh. The embodied mind and its challenge to Western thought. New York: Basic Books.

Lawlor, L. (2002a). Husserl at the limits of phenomenology. Evanston: Northwestern University Press.

Lawlor, L. (2002b). Derrida and Husserl. The basic problem of phenomenology. Bloomington and Indiana: Indiana University Press.

Merleau-Ponty, M. (1964 [1960]). Signs. (Trans: R. C. McCleary). Evanston: Northwestern University Press.

Merleau-Ponty, M. (1968 [1964]). The visible and the invisible (Trans A. Lingis). Evanston: Northwestern University Press.

Moran, D. \& Cohen, J. (2012). The Husserl dictionary. New York: Continuum International.

Noé, K. (1992). "The hermeneutic turn" in Husserl's phenomenology of language. Phenomenology and the Human Sciences in Japan 15(1): 117-128.

Schutz, A. \& Luckman, T. (1973). The structures of the life-world. Evanston: Northwestern University Press.

Stampoulidis, G., Bolognesi, M., \& Zlatev, J. (2019). A cognitive semiotic exploration of metaphors in Greek street art. Cognitive Semiotics, 12(1).

Ströker, E. (1984). Husserl's transcendental phenomenology and history. In Kah Kyung Cho (ed.) Philosophy and science in phenomenological perspective (pp. 195-207). Dortrecht: Springer.

Woelert, P. (2008). Materialisations of space: Phenomenological-archeological investigations concerning the relations between human organism, space and technology. $\mathrm{PhD}$ thesis: University of New South Wales.

Woelert, P. (2011). Human cognition, space, and the sedimentation of meaning. Phenomenology and the Cognitive Sciences 10(1): 113-137.

Zlatev, J. \& Blomberg, J. (2016). Embodied intersubjectivity, sedimentation and non-actual motion expressions. Nordic Journal of Linguistics 39(2): 185-208.

Zlatev, J. \& Blomberg, J. (2019). Norms of language: What kinds and where from? Insights from phenomenology. In A. Mäkilähde, V. Leppänen and E. Itkonen (eds.), Norms and normativity in language and linguistics (pp. 69-101). Amsterdam: Benjamins.

Author Address

Email address: johan.blomberg@semiotik.lu.se

About the Author

Johan Blomberg has a PhD in General Linguistics from 2014, for the dissertation Motion in Language and Experience. He has since then worked in the Division for Cognitive Semiotics at Lund University, to which he continues to be affiliated. His main interests include motion semantics and the relations between language and thought, on which he has published extensively in journals like Cognitive Linguistics, Frontiers of Psychology and Language and Communication. 